\title{
Inhibitory Effects of Ruta graveolens L. Extract on Guinea Pig Liver Aldehyde Oxidase
}

\author{
Pirouzpanah SaIeEd, ${ }^{a}$ Rashidi Mohammad Reza, ${ }^{*, b}$ Delazar Abbas,${ }^{b}$ Razavieh Seyyedvali, ${ }^{a}$ and \\ Hamidi ALIASGHAR ${ }^{c}$ \\ ${ }^{a}$ School of Health and Nutrition, Tabriz University of Medical Sciences, ${ }^{b}$ Drug Applied Research Center, Tabriz University \\ of Medical Sciences; and ${ }^{c}$ School of Pharmacy, Tabriz University of Medical Sciences; Tabriz 51666-14776, Iran. \\ Received May 17, 2005; accepted August 22, 2005
}

Ruta graveolens $\mathbf{L}$. is a flavonoid-containing medicinal plant with various biological properties. In the present study, the effects of $\boldsymbol{R}$. graveolens extract on aldehyde oxidase, a molybdenum hydroxylase, are investigated. Aldehyde oxidase was partially purified from liver homogenates of mature male guinea pigs by heat treatment and ammonium sulphate precipitation. The total extract was obtained by macerating the aerial parts of $R$. graveolens in $\mathrm{MeOH} \mathbf{7 0 \%}$ and the effect of this extract on the enzyme activity was assayed using phenanthridine, vanillin and benzaldehyde as substrates. Quercetin and its glycoside form, rutin were isolated, purified and identified from the extract and their inhibitory effects on the enzyme were investigated. $R$. graveolens extract exhibited a high inhibition on aldehyde oxidase activity $(89-96 \%)$ at $100 \mu \mathrm{g} / \mathrm{ml}$ which was comparable with $10 \mu \mathrm{M}$ of menadione, a specific potent inhibitor of aldehyde oxidase. $\mathrm{The}^{\mathrm{IC}} \mathrm{C}_{50}$ values for the inhibitory effect of extract against the oxidation of benzaldehyde, vanillin and phenanthridine were $10.4,10.1,43.2 \mu \mathrm{g} / \mathrm{ml}$, respectively. Both quercetin and rutin at $10 \mu_{\mathrm{M}}$ caused $70-96 \%$ and $27-52 \%$ inhibition on the enzyme activity, respectively. Quercetin was more potent inhibitor than rutin, but both flavonols exerted their inhibitory effects mostly in a linear mixed-type.

Key words Ruta graveolens L.; aldehyde oxidase; flavonoid; quercetin; rutin

Nowadays, there is a growing interest in natural healing methods, and particular efforts have been devoted to elucidating medicinal effects of natural agents in plants and the typical methods of plant extract preparation. ${ }^{1)}$ Ruta graveolens L. (Family: Rutaceae) is a medicinal plant which has been traditionally used as a sedative and antihelmintic to relieve menstrual and gastrointestinal disorders. ${ }^{2,3)}$ Also hypotensive, ${ }^{4,5)}$ antifertility, ${ }^{6-8)}$ anti-inflammatory effects have also been claimed as further analgesic actions of this plant. ${ }^{9,10)}$ Most of these biological properties that have been denoted by preceding studies are likely related to some chemical constituents including flavonoids. ${ }^{4,11)}$

Flavonoids are a group of naturally occurring phenolic compounds that are a part of primary chemical components of $R$. graveolens L.,6,11) The most important analyzed flavonoid in $R$. graveolens L. is rutin (quercetin-3-O- $\beta$-rutinoside) that belongs to flavonol glycoside. Quercetin is another major flavonoid found in $R$. graveolens $\mathrm{L}$. and can also be obtained by rutin hydrolysis (Fig. 1). The supposed therapeutic effects of many traditional medicines have been attributed to flavonoids in particular as a result of their enzyme inhibitory and antioxidant activity., ${ }^{4,2}$ Certain aglycones of flavonol have been suggested to be potent xanthine oxidase (xanthine: $\mathrm{O}_{2}$ oxidoreductase EC 1.2.3.2) inhibitors in a number of reports. ${ }^{13-18)}$ Xanthine oxidase belongs to the group of hydroxylases with molybdenum, flavin, iron and sulfur at its active site. ${ }^{19,20)}$ Xanthine oxidase has many physicochemical properties similar to those of another molybdenum-containing enzyme, aldehyde oxidase (aldehyde: $\mathrm{O}_{2}$ oxidoreductase EC 1.2.3.1). Aldehyde oxidase is a cytosolic enzyme that is widely distributed throughout the animal kingdom. ${ }^{20-24)}$ The enzyme is capable of oxidizing a wide range of xenobiotics and endogenous compounds with an aldehyde and $N$-heterocyclic structure including some important drugs such as famciclovir, methotrexate, quinine, car- bazeran and azathioprine..$^{20,22,25,26)}$ The enzyme also reduces a broad type of compounds such as sulfoxide, ${ }^{27-30)}$ azo dyes ${ }^{31,32)} N$-oxides, ${ }^{33,34)}$ nitrosamines,${ }^{28)}$ oxime, ${ }^{35)}$ nitro compounds, ${ }^{36,37)}$ epoxides, ${ }^{38)}$ and sulfonamides, ${ }^{39)}$ in the presence of an appropriate electron donor. In addition, according to previous evidences, ${ }^{40,41)}$ aldehyde oxidase may have a role in oxidative stress due to its ability to introduce oxygen-derived free radicals to living tissues.

Overall, consideration the inhibitory effects of flavonoids on xanthine oxidase and the similar structural properties of xanthine oxidase and aldehyde oxidase, it is likely there is some interactions between the chemical components of the extract and aldehyde oxidase. In the present study, therefore, the effects of $R$. graveolens $\mathrm{L}$. extract and its major active constituents on guinea pig liver aldehyde oxidase were investigated. Guinea pig liver was used as the source of enzyme because of its similarity to the human hepatic aldehyde oxidase. $^{22,42)}$

\section{Experimental \\ Materials Menadione, vanillin and phenanthridine were obtained from}

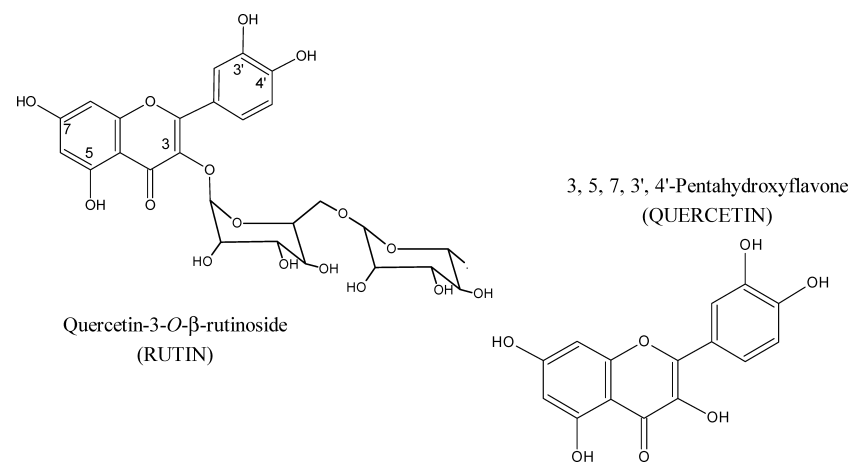

Fig. 1. Chemical Structures of Rutin and Quercetin 
Sigma (Poole, Dorset, England). All other chemicals, apart from quercetin and rutin, were purchased from Merck (Darmstadt, Germany).

Plant Material Leaves of $R$. graveolens L. were harvested from garden maintained in June 2002 at Tabriz University of Medical Science, Iran. A voucher specimen was deposited with PRTRG001, and a representative of this collection has been retained in the herbarium of the Pharmacognosy Department, Tabriz University of Medical Science. Leaves of the plant were dried at room temperature for 2 weeks and ground using an electric mill.

Extraction and Isolation The dried, ground leaves of $R$. graveolens $\mathrm{L}$. $(100 \mathrm{~g})$ were extracted with $70 \%$ methanol at room temperature followed by the evaporation of combined hydromethanolic solutions by rotatory evaporation in low pressure yielding the dried extract $(12.65 \mathrm{~g})$.

Ten grams of the dried extract was suspended in $\mathrm{H}_{2} \mathrm{O}$, and extracted with petroleum ether, chloroform, ethyl acetate and $n$-butanol to obtain the respective fractions. All these fractions were separately concentrated using a rotatory evaporator at a maximum temperature of $45^{\circ} \mathrm{C}$. The ethyl acetate fraction was subjected to column chromatography on silica gel using ethyl acetate-methanol-water $(70: 15: 5 \mathrm{v} / \mathrm{v} / \mathrm{v})$ as the mobile phase. The flow rate of the organic phase was maintained at 6 drops per minute. TLC of column chromatography fractions was carried out on silica gel plates using the mobile phase consisting of ethyl acetate-methanol-water $(65: 10: 15 \mathrm{v} / \mathrm{v} / \mathrm{v})$. The main components of the fractions of 55-70 were further purified by preparative TLC on silica gel with a mobile phase of ethyl acetate-methanol $(90: 10 \mathrm{v} / \mathrm{v})$ which resulted in the isolation of $14.6 \mathrm{mg}$ quercetin.

The $n$-butanol extract was fractioned on a Sep-Pak using a step gradient of $10,20,40,60,80$ and $100 \%$ methanol-water mixture $(150 \mathrm{ml}$ each) as the eluent. Preparative RP-HPLC (Shim-Pak CLC-C18, $6 \times 150 \mathrm{~mm}$ i.d.); gradient elution, $25-70 \%$ methanol in water in $50 \mathrm{~min}(20 \mathrm{ml} / \mathrm{min})$ of the SepPak fraction ( $60 \%$ methanol in water) yielded $82.8 \mathrm{mg}$ rutin. The structures of the both compounds were determined conclusively by UV spectroscopy, ${ }^{1} \mathrm{H}$ - and ${ }^{13} \mathrm{C}$-NMR analysis. ${ }^{43,44)}$

Enzyme Preparation Partially purified molybdenum hydroxylases were prepared from mature male Dunkin-Hartley guinea pig liver $(400-600 \mathrm{~g}$, Tabriz University of Medical Sciences) according to the method of Johnson et $a .^{45)}$ Briefly, the animal was killed between 9:00-10:00 a.m. by cervical dislocation, and the liver was immediately excised and placed in ice-cold isotonic potassium chloride solution $(1.15 \% \mathrm{KCl} \mathrm{w} / \mathrm{v})$ containing $0.1 \mathrm{~mm}$ EDTA. Then, the liver was homogenized at $3000-4000 \mathrm{rpm}$ for $1 \mathrm{~min}$ at $4{ }^{\circ} \mathrm{C}$ using Potters homogenizer. The homogenate was heated on a steam bath at $55-57^{\circ} \mathrm{C}$ for $10 \mathrm{~min}$, cooled to $4^{\circ} \mathrm{C}$ and centrifuged at $15000 \boldsymbol{g}$ for $45 \mathrm{~min}$ at $4^{\circ} \mathrm{C}$ and the supernatant was treated by $50 \%$ saturated solution of ammonium sulphate $(35.3 \mathrm{~g} / 100 \mathrm{ml})$ at $4{ }^{\circ} \mathrm{C}$. The resulting suspension was re-centrifuged at $6000 \mathrm{~g}$ for $20 \mathrm{~min}$ at $4{ }^{\circ} \mathrm{C}$. The precipitate was dissolved in a minimum volume of $0.1 \mathrm{~mm}$ EDTA solution and then was kept at $-86^{\circ} \mathrm{C}$ until use.

Enzyme Assays All spectrophotometric determinations were carried out at $37^{\circ} \mathrm{C}$ using a Shimadzu 2550 UV/VIS spectrophotometer which was controlled by the Shimadzu UV Probe personal software package including kinetics software. The instrument was connected to a Shimadzu cell temperature control unit. The cuvette used had a path length of $1 \mathrm{~cm}$ and the total volume was constant at $3.0 \mathrm{ml}$.

Aldehyde oxidase activity was determined using phenanthridine $(50 \mu \mathrm{M})$, benzaldehyde $(100 \mu \mathrm{M})$ and vanillin $(50 \mu \mathrm{M})$ as substrates by measuring the change in the absorbance at 322, 249 and $310 \mathrm{~nm}$, respectively. Each substrate was separately incubated with the enzyme fraction in Sorenson's phosphate buffer $\mathrm{pH} 7.0$ containing $0.1 \mathrm{~mm}$ EDTA and the initial oxidation rates were measured up to $2 \mathrm{~min}$. The reactions were also measured in the presence of $R$. graveolens L. extract $(100 \mu \mathrm{g} / \mathrm{ml})$, and quercetin $(10 \mu \mathrm{M})$ and rutin $(10 \mu \mathrm{M})$. The results were also compared with the inhibitory effect of menadione $(10 \mu \mathrm{M})$ (specific aldehyde oxidase inhibitor).

$K_{\mathrm{m}}$ (Michaelis-Menten constant) and $V_{\max }$ (maximum initial velocity) values for the oxidation of vanillin, phenanthridine and benzaldehyde by guinea pig liver fraction were determined spectrophotometrically from a Lineweaver-Burke double reciprocal plot of $1 / \mathrm{v}$ against $1 /[\mathrm{S}]$. The line of the best fit through the points on the plot was calculated using linear regression by the least square method. The reactions were also studied in the presence of quercetin and rutin and the inhibition constants were determined using secondary plot (slopes and intercepts from the initial LineweaverBurk plot vs. inhibitor concentrations). In the case of mixed inhibition where inhibitor can bind to the free enzyme and to the enzyme-substrate complex, two inhibitor constants were defined: $\mathrm{Ki}$ as the dissociation constant of the enzyme-inhibitor complex, and $\mathrm{K}_{\mathrm{I}}$ as the dissociation constant of the enzyme-substrate-inhibitor complex. If $\mathrm{Ki}<\mathrm{K}_{\mathrm{I}}$, the inhibition was considered as a competitive-noncompetitive type of the inhibition; if $\mathrm{Ki}>\mathrm{K}_{\mathrm{I}}$, the inhibi- tion was considered as uncompetitive-noncompetitive type.

The $\mathrm{IC}_{50}$ values of $R$. graveolens $\mathrm{L}$. extract, quercetin and rutin were obtained from the inhibitor concentration-activity curve.

Protein Determination Protein concentrations of partially purified enzyme fractions were determined spectrophotometrically using a Pierce BCA Protein assay kit with bovine serum albumin as a protein standard. ${ }^{46)}$

\section{Results}

The ${ }^{1} \mathrm{H}$ - and ${ }^{13} \mathrm{C}-\mathrm{NMR}$ of the isolated compounds revealed the chemical shifts of protons and carbons essentially identical with those reported in the literature for quercetin and rutin. ${ }^{43,44)}$ The chemical structure of quercetin and rutin also have been confirmed by analysis of the UV spectra of the compounds with the diagnostic shift reagents. ${ }^{43}$

The inhibition of aldehyde oxidase activities by $R$. graveolens L. extract and its major flavonoids, quercetin and rutin along with menadione and allopurinol, have been tabulated in Table 1. As it was expected, all three oxidations were inhibited by $10 \mu \mathrm{M}$ menadione, the potent inhibitor of aldehyde oxidase. In contrast, allopurinol, a mechanism-based potent inhibitor of xanthine oxidase, at concentration of even 100 $\mu \mathrm{M}$ caused 19.5 and $10.4 \%$ inhibition on the benzaldehyde and vanillin oxidations, respectively. This inhibition arises from allopurinol acting as a competitive substrate for aldehyde oxidase rather than its inhibitory effect on xanthine oxidase which is present in the enzyme fraction. Therefore, the partially purified guinea pig liver fraction prepared in this study can be used as a source for aldehyde oxidase, and under the experimental conditions used the enzyme activity can be measured with no significant interference from xanthine oxidase. $R$. graveolens L. extract and its flavonoids inhibited aldehyde oxidase activity. Quercetin was found to be more potent inhibitor than its glycoside, rutin against the enzyme. The inhibitory effect of quercetin on aldehyde oxidase activity was comparable to that of menadione. However, the oxidation of phenanthridine, an $N$-heterocyclic substrate of aldehyde oxidase, was relatively less affected by both

Table 1. Inhibition of Guinea Pig Liver Aldehyde Oxidase by Menadione, Allopurinol, R. graveolens L. Extract, Quercetin and Rutin ${ }^{a)}$

\begin{tabular}{lcrr}
\hline \hline Inhibitors & $\begin{array}{c}\text { Benzaldehyde } \\
(100 \mu \mathrm{M})\end{array}$ & $\begin{array}{c}\text { Phenanthridine } \\
(50 \mu \mathrm{M})\end{array}$ & $\begin{array}{c}\text { Vanillin } \\
(50 \mu \mathrm{M})\end{array}$ \\
\hline $\begin{array}{l}\text { R. graveolens L. extract } \\
(100 \mu \mathrm{g} / \mathrm{ml})\end{array}$ & $90.1 \pm 0.2$ & $96.3 \pm 6.1$ & $89.1 \pm 9.2$ \\
Quercetin $(10 \mu \mathrm{M})$ & $96.2 \pm 6.1$ & $69.5 \pm 5.4$ & $91.3 \pm 4.2$ \\
Rutin $(10 \mu \mathrm{M})$ & $52.2 \pm 4.1$ & $26.7 \pm 7.8$ & $34.1 \pm 5.3$ \\
Menadione $(10 \mu \mathrm{M})$ & $80.5 \pm 12.2$ & $96.3 \pm 4.1$ & $89.6 \pm 9.3$ \\
Allopurinol $(100 \mu \mathrm{M})$ & $13.4 \pm 8.4$ & $6.2 \pm 4.2$ & $7.1 \pm 4.0$ \\
\hline
\end{tabular}

a) The results are expressed as percentage inhibition (mean \pm S.D., $n=3$ ).

Table 2. $\quad \mathrm{IC}_{50}$ Values of $R$. graveolens L. Extract, Quercetin and Rutin for Inhibition of Guinea Pig Liver Aldehyde Oxidase ${ }^{a}$

\begin{tabular}{lrrr}
\hline \hline Inhibitors & $\begin{array}{r}\text { Benzaldehyde } \\
(100 \mu \mathrm{M})\end{array}$ & $\begin{array}{r}\text { Vanillin } \\
(50 \mu \mathrm{M})\end{array}$ & $\begin{array}{r}\text { Phenanthridine } \\
(50 \mu \mathrm{M})\end{array}$ \\
\hline R. graveolens L. extract & $10.4 \pm 1.3$ & $10.1 \pm 2.9$ & $43.2 \pm 4.2$ \\
Quercetin & $0.6 \pm 0.2$ & $0.5 \pm 0.3$ & $4.3 \pm 1.4$ \\
Rutin & $8.9 \pm 2.1$ & $14.1 \pm 4.3$ & $25.1 \pm 6.8$ \\
\hline
\end{tabular}

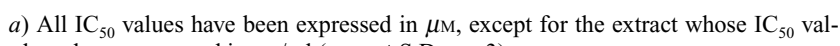
ues have been expressed in $\mu \mathrm{g} / \mathrm{ml}$ (mean \pm S.D., $n=3$ ). 
Table 3. Kinetic Characteristics of Inhibitory Activity of Quercetin and Rutin on the Oxidation of Benzaldehyde, Vanillin and Phenanthridine by Guinea Pig Liver Aldehyde Oxidase

\begin{tabular}{|c|c|c|c|c|c|c|}
\hline & \multicolumn{3}{|c|}{ Quercetin } & \multicolumn{3}{|c|}{ Rutin } \\
\hline & $\mathrm{Ki}(\mu \mathrm{M})$ & $\mathrm{K}_{\mathrm{I}}(\mu \mathrm{M})$ & Mode of inhibition & $\mathrm{Ki}(\mu \mathrm{M})$ & $\mathrm{K}_{\mathrm{I}}(\mu \mathrm{M})$ & Mode of inhibition \\
\hline Benzaldehyde & $0.5 \pm 0.2^{a)}$ & $0.4 \pm 0.1$ & Mixed & $47.2 \pm 2.8$ & $10.1 \pm 0.7$ & Mixed \\
\hline Phenanthridine & $0.8 \pm 0.1$ & $1.7 \pm 1.1$ & Mixed & $25.8 \pm 4.2$ & - & Non-competitive \\
\hline Vanillin & $0.4 \pm 0.1$ & $0.5 \pm 0.1$ & Mixed & $28.5 \pm 3.4$ & $9.2 \pm 0.9$ & Mixed \\
\hline
\end{tabular}

a) The results are expressed as mean \pm S.D. $\mu \mathrm{M}, n=3-4$.

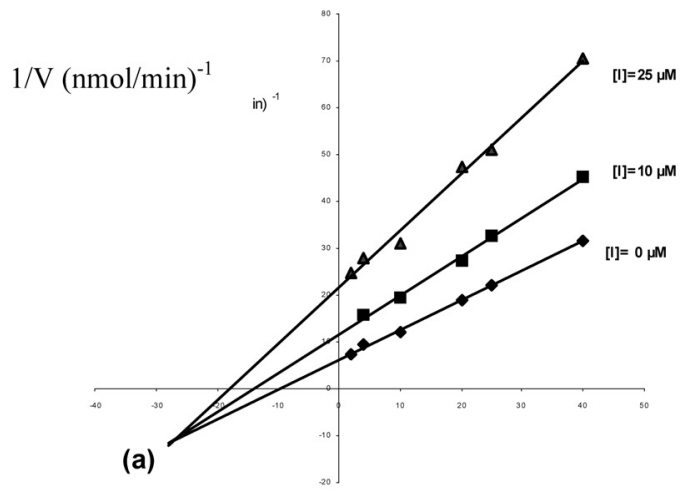

$1 /\left[\right.$ Vanillin] $\mu \mathrm{M}^{-1}$

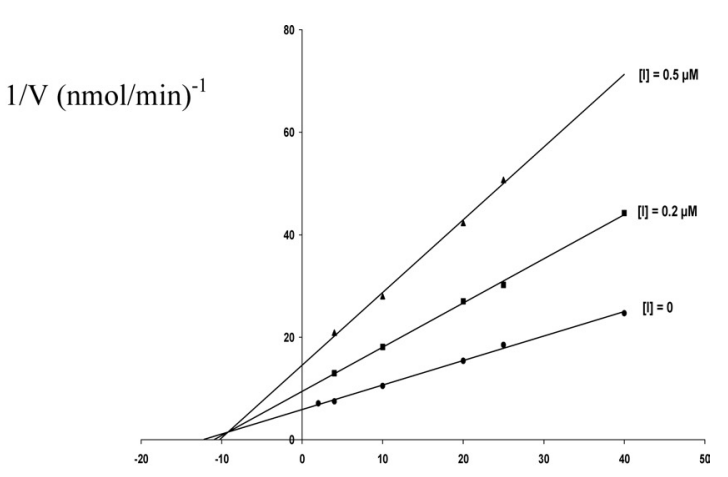

(b)

1/[Vanillin] $\mu \mathrm{M}^{-1}$

Fig. 2. Typical Lineweaver-Burk Plots for Inhibitory Activity of Rutin (a) and Quercetin (b) on the Oxidation of Vanillin Catalyzed by Guinea Pig Liver Aldehyde Oxidase

The enzyme assays were performed as described in Materials and Methods. The data represent the average of $3-5$ experiments.

flavonoids than benzaldehyde and vanillin oxidations, the aldehyde substrates of the enzyme.

The $\mathrm{IC}_{50}$ values of $R$. graveolens $\mathrm{L}$. extract and the flavonoids are summarized in Table 2. The extract, quercetin and rutin exerted their inhibitory effects in a dose-dependent manner and quercetin was observed to be the most potent inhibitor against aldehyde oxidase activity.

The kinetic parameters for inhibition of benzaldehyde, phenanthridine and vanillin oxidations by quercetin and rutin are summarized in Table 3 . The kinetics analysis of the reactions revealed that quercetin exerts its inhibitory effect on aldehyde oxidase with either the aldehyde or the $N$-heterocycle substrates through a mixed type of inhibition, although in the case of the former group the inhibition constants were close to each other (Fig. 2, Table 3). In addition, the $\mathrm{K}_{\mathrm{I}}$ value of quercetin for the benzaldehyde oxidation was lower than the corresponding $\mathrm{Ki}$ value, whereas for the oxidation of vanillin and in particular phenanthridine, the Ki values were lower than the corresponding $\mathrm{K}_{\mathrm{I}}$ values indicating a mixed inhibition with a pronounced competitive tendency.

Although both rutin and quercetin inhibited benzaldehyde and vanillin oxidations in a mixed mode of inhibition, rutin was found to be a non-competitive inhibitor of phenanthridine oxidation (Table 3 ).

\section{Discussion}

Aldehyde oxidase is a dominant enzyme in metabolization of several xenobiotics including some important drugs. ${ }^{20)}$ Aldehyde oxidase utilizes molecular oxygen as the acceptor of electrons released during the substrate oxidation, therefore it is also expected to accompany in endogenic oxidative stress. ${ }^{41)}$ In spite of growing interest in traditional use of medicinal plants, a few studies have been carried out on the effects of herbal medicinal materials on aldehyde oxidase activity. ${ }^{47)} R$. graveolens $\mathrm{L}$. is a herbaceous plant which is rich in flavonoids. ${ }^{4}$ ) These polyhydroxylic compounds are major components of fruits, vegetables, grains and seeds. It has been shown that some of these natural components such as quercetin, catechin, apigenin, kaempferol, myricetin and genistein have potent inhibitory effects on xanthine oxidase, one of two major molybdenum hydroxylases. ${ }^{15-18)}$ Because of many structural similarities between xanthine oxidase and other molybdenum hydroxylase, aldehyde oxidase, it is more likely that the $R$. graveolens $\mathrm{L}$. extract which is rich in flavonoids, may have some interferes with aldehyde oxidase activity.

The obtained results in the present study indicated that both the total extract and the major flavonoids of $R$. graveolens L., quercetin and rutin, are able to inhibit guinea pig hepatic aldehyde oxidase activity. The inhibitory effect of quercetin on the enzyme was found to be as potent as menadione, the known specific inhibitor of aldehyde oxidase. ${ }^{20)}$ However, the extent of inhibition induced by $R$. graveolens $\mathrm{L}$. flavonoids on the oxidation of phenanthridine, as an $\mathrm{N}$-heterocyclic substrate of aldehyde oxidase, was apparently different from the observed results for benzaldehyde and vanillin, as the aldehyde oxidase substrate with aldehyde structures (Table 1).

On the other hand, both quercetin and rutin acted as relatively more potent inhibitors on benzaldehyde and vanillin oxidation than the phenanthridine oxidation catalyzed by aldehyde oxidase. It is likely that the manner of aldehyde ox- 
idation by guinea pig liver aldehyde oxidase is different from that of phenanthridine. This could be anticipated by whether different isoforms of aldehyde oxidase in the oxidation of benzaldehyde, which is supported by other studies, ${ }^{20,42}$ are probably involved or it is also likely that flavonoids interact with benzaldehyde and phenanthridine oxidations which are catalyzed by aldehyde oxidase in a different manner.

Lineweaver-Burk transformation of the inhibition data indicated that quercetin and rutin exert their inhibition on benzaldehyde and vanillin oxidations via mixed type; however, their interactions with the enzyme were different from each other. Quercetin was found to be more potent inhibitor of aldehyde oxidase-catalyzed oxidations of the both aldehydes than rutine. In addition, the $\mathrm{Ki}$ and $\mathrm{K}_{\mathrm{I}}$ values for the inhibition of these two reactions by quercetin were almost similar, whereas rutin showed more affinity to the enzyme-substrate complex than to the free enzyme $\left(\mathrm{Ki}>\mathrm{K}_{\mathrm{I}}\right)$ with both aldehyde oxidations.

In the case of catalytic phenanthridine oxidation, quercetin has been also demonstrated to have low affinity to the free enzyme (see Table 3). In agreement with outcomes from benzaldehyde and vanillin oxidations, rutin was found to be a weak inhibitor of phenanthridine oxidation compared with quercetin, however, the glycoside inhibited the phenanthridine oxidation in a non-competitive manner. The low inhibition constants of both flavonoids for induction of inhibitory activity on benzaldehyde and vanillin compared with phenanthridine oxidation are in concordance with the $\mathrm{IC}_{50}$ values obtained for these reactions (Table 3).

These results are also in agreement with the resulted $K_{\mathrm{m}}$ values. Phenanthridine was confirmed to be a well substrate catalyzed by aldehyde oxidase with a $K_{\mathrm{m}}$ value of $4.1 \pm 1.5$ $\mu \mathrm{M}$ than benzaldehyde and vanillin with $K_{\mathrm{m}}$ values of $13.4 \pm 3.1$ and $9.2 \pm 1.7 \mu \mathrm{M}$, respectively. ${ }^{20}$ )

It has been comprehensively shown that the substitution of hydroxyl group at C-3 of C ring by sugar molecules (Fig. 1) influences inhibitory activity of flavonoids on molybdenum hydroxylases. Accordingly, in all studies, quercetin has been found to be a more potent inhibitor of xanthine oxidase than its glycosylated form, rutin. ${ }^{15-18)}$ Consistent with the evidence for xanthine oxidase, ${ }^{48,49)}$ quercetin was found to be a more potent inhibitor of aldehyde oxidase than rutin. It solely appears that substitution of hydroxyl group at C-3 of flavonoids results in a reduction in the inhibitory potencies of these polyhydroxylic natural compounds. Similarly, identical structural characteristics have been reported for structure-activity-relationship of steroids and aldehyde oxidase. It has been shown that substitution of hydroxyl group at C-3' of $\mathrm{A}$ ring in $\beta$-estradiol reduces the inhibitory effect of steroid on aldehyde oxidase activity. ${ }^{50,51)}$

For the first time, it was demonstrated in the present study that $R$. graveolens L. with a high content of flavonoids is capable of serving as a potent inhibitor against aldehyde oxidase activity. Hence, as these natural flavonoids are distributed widely in vegetables and fruits, food-drug interactions between aldehyde oxidase-catalyzed-related reactions such as metabolism of some custom drugs can be expected, as can flavonoid-containing foods, the later being a subject for further investigations.
Acknowledgement The author would like to thank Research Affairs Office of Tabriz University of Medical Sciences for its financial support.

\section{References}

1) Qicheng F., J. Ethnopharmacol., 2, 57-63 (1980).

2) Guarrera P. M., J. Ethnopharmacol., 15, 183-192 (1999).

3) Skidmore-Roth L., "Mosby's Handbook of Herbs and Natural Supplements," 1st ed., Mosby, New York, 2001, pp. 741-744.

4) Chiu K. W., Fung A. Y., Gen. Pharmacol., 29, 8590-8862 (1997).

5) Trovato A., Monforte M. T., Forestieri A. M., Pizzimenti F., Boll. Chim. Farm., 139, 225-227 (2000).

6) Gandhi M., Lal R., Sankaranarayanan A., Sharma P. L., J. Ethnopharmacol., 34, 49-59 (1991).

7) Kong Y. C., Lau C. P., Wat K. H., Ng K. H., But P. P., Cheng K. F., Waterman P. G., Planta Med., 55, 176-178 (1989).

8) Al-Okbi S. Y., El-Sayed E. M., Ammar N. M., El-Sayed N. K., AbouEl Kassem L. T., Indian J. Exp. Biol., 40, 45-48 (2002).

9) Atta A. H., Alkofahi A., J. Ethnopharmacol., 60, 117-124 (1998).

10) Middleton J. R. E., Chithan K., Theoharides C. T., Pharmacol. Rev., 52, 673-751 (2000).

11) Chen C. C., Huang Y. L., Huang F. I., Wang C. W., Ou J. C., J. Nat. Prod., 64, 990-992 (2001).

12) Havsteen B., Biochem. Pharmacol., 1, 1141-1148 (1983).

13) Lio M., Ono Y., Kai S., Fukumoto M., J. Nutr. Sci. Vitaminol. (Tokyo), 32, 635-642 (1986).

14) Chang W. S., Lee Y. J., Lu F. J., Chiang H. C., Anticancer Res., 13, 2165-2170 (1993).

15) Aucamp J., Gaspar A., Hara Y., Anticancer Res., 17, 4381-4386 (1997).

16) Robak J., Gryglewski R. J., Biochem. Pharmacol., 37, 837-841 (1998).

17) Selloum L., Reichl S., Muller M., Sebihi L., Arnhold J., Arch. Biochem. Biophys., 395, 49-56 (2001).

18) Van Hoorn E. C. D., Nijveldt R. J., van Leeuwen P. A. M., Hofman Z., Rabet L. M., De Bont D. B. A., Van Norren K., Eur. J. Clin. Pharmacol., 451, 111-118 (2002).

19) Mahler H. R., Fairhurst A. S., Mackler B., J. Am. Chem. Soc., 77, 1514-1521 (1995).

20) Beedham C., "Enzymes Systems that Metabolize Drugs and Other Xenobiotics," ed. by Ioannides C., John Wiley \& Sons, New York, 2002, pp. 148-177.

21) Hille R., Massay V., "Molybdenum Enzyme,” ed. by Spiro T. G. M., John Wiley \& Sons, New York, 1985.

22) Beedham C., "Progress in Medicinal Chemistry," Vol. 24, ed. by Ellis G. P., West G. B., Elsevier, Amsterdam, 1987, pp. 85-127.

23) Ciang H. C., Lo Y. J., Lu F. J., J. Enzyme Inhib., 8, 61-71 (1994).

24) Maia L., Mira L., Arch. Biochem. Biophys., 400, 48-53 (2002).

25) Jordan C. G., Rashidi M. R., Laljee H., Clarke S. E., Brown J. E., Beedham C., J. Pharm. Pharmacol., 51, $411-418$ (1999).

26) Rashidi M. R., Smith J. A., Clarke S. E., Beedham C., Drug Metab. Dispos., 25, 805-813 (1997).

27) Kitamura S., Tatsumi K., Hirata Y., Yoshimura H., J. Pharmacodyn, 4, 528-533 (1981).

28) Tatsumi K., Yamada H., Kitamura S., Chem. Pharm. Bull., 31, 764767 (1983).

29) Lee S. C., Renwick A. G., Biochem. Pharmacol., 49, 1557-1565 (1995).

30) Tatsumi K., Kitamura S., Yamada H., Biochim. Biophys. Acta, 747, 86-92 (1983).

31) Kitamura S., Nakatani K., Ohashi K., Sugihara K., Hosokawa R., Akagawa Y., Ohta S., Biol. Pharm. Bull., 24, 856-859 (2001).

32) Stoddart A. M., Levine W. G., Biochem. Pharmacol., 43, 2227-2235 (1992).

33) Sugihara K., Kitamura S., Tatsumi K., Biochem. Mol. Biol. Int., 40, 535-541 (1996).

34) Kitamura S., Tatsumi K., Biochem. Biophys. Res. Commun., 121, 749-754 (1984).

35) Tatsumi K., Ishigai M., Arch. Biochem. Biophys., 253, 413-418 (1987).

36) Tatsumi K., Kitamura S., Narai N., Cancer Res., 46, 1089-1093 (1986).

37) Hirao Y., Kitamura S., Tatsumi K., Carcinogenesis, 15, 739-743 (1994).

38) Dick R. A., Kanne D. B., Casida J. E., Chem. Res. Toxicol., 18, 317 
323 (2005).

39) Sugihara K., Kitamura S., Tatsumi K., Drug Metab. Dispos., 24, 199 202 (1996).

40) Mira L., Maia L., Barreira L., Manso C. F., Arch. Biochem. Biophys., 318, 53-58 (1995).

41) Halliwell B., Cutteridge M. C., "Free Radicals in Biology and Medicine," 3rd ed., Oxford University Press, New York, 1999.

42) Kawashima K., Hosoi K., Naruke T., Shiba T., Kitamura M., Drug Metab. Dispos., 27, 422-428 (1999).

43) Mabry T. J., Markham K. R., Thomas M. B., "The Systematic Identification of Flavonoids," Spring-Verlag, New York, 1970, pp. 335-345.

44) Breitmaier E., Voelter W., "Carbon-13 NMR Spectroscopy," VCH Verlagsgesellschaft, New York, 1989, pp. 450-457.

45) Johnson C., Stubley-Beedham C., Stell J. G., Biochem. Pharmacol, 15, 4251-4256 (1985).
46) Smith P. K., Krohn R. I., Hermanson G. T., Mallia A. K., Gartner F. H., Provenzano M. D., Fujimoto E. K., Goeke N. M., Olson B. J., Klenk D. C., Anal. Biochem., 150, 76-85 (1985).

47) Choi J., Yoon B. J., Han Y. N., Lee K. T., Ha J., Jung H. J., Park H. J., Planta Med., 69, 899-904 (2003).

48) Cos P., Ying L., Calomme M., Hu J. P., Cimanga K., Van Poel B., Pieters L., Viletinck A. J., Berghe D. V., J. Nat. Prod., 61, 71-76 (1998).

49) Nagao A., Seki M., Kobayashi H., Biosci. Biotechnol. Biochem., 63, 1787-1790 (1999).

50) Huh K., Shin U. S., Choi J. W., Lee S. I., Arch. Pharmacol. Res., 17, $109-114$ (1994).

51) Lee D. U., Shin U. S., Huh K., Arch. Pharmacol. Res., 21, 273-277 (1998). 